\title{
PLANO NACIONAL DE EDUCAÇÃO: EPICENTRO DAS POLÍTICAS DE ESTADO PARA A EDUCAÇÃO BRASILEIRA*
}

\author{
Maria Margarida Machado ${ }^{1}$
}

A s reflexóes propostas pelo Professor Luiz Dourado (2017) neste livro 4 nos remetem ao contexto de lutas e mobilizaçóes nacionais para a cons11 tituição de um Sistema Nacional de Educação. Iniciativas importantes, desde o início da década de 1930, com destaque para a publicação do Manifesto dos pioneiros da educação nova em 1932, colocam em questão, até os dias atuais, o desafio da materialização de políticas de Estado para a educação brasileira. Essa primeira iniciativa de proposição de um plano nacional de educação, forjado no seio da sociedade civil, dirigido ao povo e ao governo, convocando para a reconstrução educacional no Brasil, posteriormente se soma às preocupações de Anísio Teixeira, expressas no parágrafo final do Plano Nacional de Educação (PNE), por ele redigido em 1962,

\begin{abstract}
Tão retardado se acha o país no desempenho de suas obrigaçóes constitucionais e legais de oferecer educação primária a tôda sua população e educação média e superior em quantidades compatíveis com o seu desenvolvimento, que sòmente com o mais rigoroso espírito de planejamento e a mais severa preocupação contra o desperdício e o esfôrço improdutivo é que poderemos vencer o ameaçador atraso em que nos encontramos na meta das metas, que é a do desenvolvimento dos recursos humanos do nosso país (DOURADO, 2017, p. 31).
\end{abstract}

Esse esforço de evidenciar a educação como "meta das metas" chega ao século XXI consubstanciado por um movimento crescente de participação e mobilização em torno da pauta da educação, incidindo sobre a aprovação da Lei no 13.005/2014, que trata do Plano Nacional de Educação 2014-2024. Como afirma Dourado (2017, p. 18),

[...] é fundamental lançar luz nos esforços múltiplos de monitoramento e avaliação do PNE, oriundos das instâncias com responsabilidades institucionais nesse campo, bem como situar os movimentos e políticas em curso após a aprovação do PNE.

\footnotetext{
*Resenha do livro: DOURADO, L.F. Plano Nacional de Educação: o epicentro das políticas de estado para a educação brasileira. Goiânia: Imprensa Universitária/ANPAE, 2017.

${ }^{1}$ Universidade Federal de Goiás - Goiânia (GO), Brasil. E-mail: mmm2404@gmail.com DOI: 10.1590/ES0101-73302018189473
} 
Todavia, isso não basta. Para esse autor é necessário que o PNE alcance, efetivamente, a condição de epicentro das políticas de Estado para a educaçáo. $\mathrm{Ou}$, como ele mesmo reafirma, tomadas sob esse prisma, políticas e gestão da educaçáo expressam:

Uma tessitura sociopolítica complexa, que se articula às agendas transnacionais, ao Estado nacional, à relação entre entes federados, às especificidades do sistema educacional brasileiro, à gestáo, à avaliação e ao financiamento, à qualidade e às concepçốes político-pedagógicas norteadoras, entre outros. A defesa da centralidade não negligencia ou desconhece limites na formulação do PNE, mas tem por eixo o esforço realizado, por meio de ampla participação da sociedade civil e política, em direção a um Plano de Estado para a educação brasileira, visando à garantia do direito a educação para todos/as (DOURADO, 2017, p. 176).

Portanto, tornar-se epicentro é, para além de um lugar no âmbito da construção da política, uma tomada de consciência sob o seu caráter processual. Isso coloca o PNE 2014-2024 como o resultado possível de uma constituição hegemônica da pauta educacional brasileira, na chegada à segunda década do século XXI. Um exercício, no Estado Integral (GRAMSCI, 2007), de diálogo e proposição entre sociedade civil e sociedade política.

Ancorado no suporte teórico e metodológico gramsciano, sobretudo na concepção de Estado e educação, o autor organiza os três capítulos do livro, partindo da contextualização histórica dos planos; apresenta uma avaliação do PNE 2014-2024, a partir de notas teóricas destacando avanços, limites e ambiguidades do plano, demonstrando a não linearidade entre proposiçóes e materializaçóes das políticas. Analisa, no Capítulo 3, as 20 metas do PNE, agrupadas em quatro eixos: educação básica, educação superior, valorização dos profissionais da educação, e gestáo democrática e financiamento da educação. Antes das consideraçóes finais, o autor ainda apresenta os diferentes dispositivos usados pelo governo federal, sobretudo após o impeachment da Presidenta Dilma, em 2016, que revelam um cenário de retrocessos e comprometem a materialização do PNE.

O contexto histórico de elaboração, aprovação e implementação das leis educacionais brasileiras é marcado por processos tensos e intensos, de tentativas de construção de consensos, em meio a muitos mecanismos coercitivos. Os projetos de lei, planos de governo, leis e decretos, impulsionados por manifestos e conferências, revelam as lutas travadas entre sociedade política e sociedade civil, bem como no interior de cada uma delas. Disputas permanentes, nesses processos, giram em torno dos interesses públicos e privados, bem como das defesas pela desresponsabilização do Estado para com a educação, pela via dos mecanismos de descentralização versus centralização, por fim, da explicitação de concepções inconciliáveis de educação: de um lado a perspectiva emancipatória 
e de formação humana integral; de outro a visão de uma educação que serve aos interesses do mercado. Finalizando essa retrospectiva, o autor afirma:

Identificar e analisar esse quadro histórico - cuja centralidade vem se traduzindo pelas políticas e açôes de Governo, em detrimento de políticas de Estado e cujas lógicas e dinâmicas de planejamento, gestão e financiamento não contribuem, efetivamente, para se avançar na construção coletiva e efetivação de políticas de Estado - é fundamental, sobretudo se consideramos o esforço histórico a ser feito para garantir a efetiva materialização do Plano Nacional de Educação (PNE 2014-2024), aprovado e sancionado, sem vetos, por meio da Lei no $13.005 / 2014$, após quase quatro anos de complexa e disputada tramitaçáo no Congresso Nacional (DOURADO, 2017, p. 39-40).

A explicitação dos desafios postos ao PNE 2014-2024, mesmo após sua aprovação sem vetos, dá-se pela necessidade de sua materialização. $\mathrm{O}$ autor, além do referencial gramsciano para pensar o Estado, a correlação de forças contraditórias, a resultante de uma hegemonia encouraçada de coerção etc., aprofunda as questóes da efetivação das políticas, à luz das reflexóes de Stephen J. Ball, em sua teoria sobre o ciclo de políticas, quando afirma que: "A prática é composta de muito mais do que a soma de uma gama de políticas e é tipicamente investida de valores locais e pessoais e, como tal, envolve a resoluçáo de, ou luta com, expectativas e requisitos contraditórios - acordos e ajustes secundários fazem-se necessários" (DOURADO, 2017, p. 43).

Com sua explicitação, as expectativas, os requisitos contraditórios, os acordos e os ajustes secundários ficam evidentes no processo de tramitação e aprovação da Lei no $n^{\circ}$ 13.005/2014. Como parte integrante de um processo de intensas mobilizaçôes da sociedade civil, com destaque para as conferências de educação e de implementação de vários programas e políticas no âmbito federal, desde 2003, o PNE 2014-2024 é resultante do "duplo papel ideológico desse movimento - a negação e, paradoxalmente, a participação da sociedade nas questōes educacionais - mediatizado por uma concepção política, cuja égide consiste, no campo dos direitos sociais, na prevalência de uma cidadania regulada e, consequentemente, restrita" (DOURADO, 2017, p. 46).

O terceiro e último capítulo, robusto em tamanho e densidade empírica, analisa as 20 metas do PNE 2014-2024, problematizando potencialidades e limites para a sua materializaçáo. Tomando como referência para suas reflexóes o Relatório do $1^{\circ}$ ciclo de monitoramento das metas do PNE: biênio 2014-2016, produzido pelo Instituto de Estudos e Pesquisas Educacionais Anísio Teixeira (INEP), apresenta um conjunto de dados e análises sobre os desafios da realidade da educação, em todas as suas etapas, níveis e modalidades, mantendo sua defesa inconteste de uma educação pública, gratuita, de qualidade social, laica e democrática, bem 
como da regulamentação do setor privado e sua democratizaçáo, perante a tensa relação quantidade e qualidade.

As reflexóes, ao final dessa obra, convocam-nos para a luta, o que nos remete a Cury (2002), que já afirmava no início do século XXI:

A importância da lei não é identificada e reconhecida como um instrumento linear ou mecânico de realização de direitos sociais. Ela acompanha o desenvolvimento contextuado da cidadania em todos os países. A sua importância nasce do caráter contraditório que a acompanha: nela sempre reside uma dimensão de luta. Luta por inscriçôes mais democráticas, por efetivaçôes mais realistas, contra descaracterizaçōes mutiladoras, por sonhos de justiça. Todo o avanço da educação escolar além do ensino primário foi fruto de lutas conduzidas por uma concepção democrática da sociedade em que se postula ou a igualdade de oportunidades ou mesmo a igualdade de condiçôes sociais (CURY, 2002, p. 247).

Corroborando Cury (2002), a defesa do PNE 2014-2024, pelo Professor Luiz Dourado, como epicentro das políticas de Estado para a educação brasileira, insere-se num contexto de lutas e resistências que a sociedade civil do campo da educaçáo vem empreendendo por meio do Fórum Nacional Popular de Educação (FNPE) e da construção coletiva da Conferência Nacional Popular de Educação (CONAPE), prevista para 2018.

\section{Referências}

CURY, C.R.J. Direito a educação: direito à igualdade, direito à diferença. Cadernos de Pesquisa, n. 116, p. 245-262, jul. 2002.

GRAMSCI, A. Cadernos do cárcere. Maquiavel. Notas sobre o Estado e política. 3a. ed. Edição e tradução de Carlos Nelson Coutinho. Coedição de Luiz Sérgio Henriques e Marco Aurélio Nogueira. Rio de Janeiro: Civilização Brasileira, 2007. v. 3.

TEIXEIRA, A. Plano nacional de educação. Referente aos fundos nacionais de ensino primário, médio e superior. Documenta, Rio de Janeiro, n. 8, p. 24-31, out. 1962. Disponível em: $\leq$ http://www.bvanisioteixeira.ufba.br/artigos/plano1.html. Acesso em: 20 dez. 2017.

Recebido em 22 de dezembro de 2017.

Aceito em 01 de fevereiro de 2018.

(C) 2018 Centro de Estudos Educação e Sociedade - CEDES Este é um artigo de acesso aberto distribuído nos termos de licença Creative Commons. 